\title{
A combined spectrum sensing method based DCT for cognitive radio system
}

\author{
Muntasser S. Falih, Hikmat N. Abdullah
}

Department of Information and Communication Engineering, Al-Nahrain University, Iraq

\begin{tabular}{|c|c|}
\hline Article Info & ABSTRACT \\
\hline Article history: & In this paper a new hybrid blind spectrum sensing method is proposed. \\
\hline Received Jun 15,2019 & The method is designed to enhance the detection performance of \\
\hline Revised Oct 23, 2019 & Conventional Energy Detector (CED) through combining it with a proposed \\
\hline Revised Uct 23,2019 & sensing module based on Discrete Cosine Transform (DCT) coefficient's \\
\hline Accepted Nov 3, 2019 & $\begin{array}{l}\text { relationship as operation mode at low Signal to Noise Ratio (SNR) values. } \\
\text { In the proposed sensing module a certain factor called Average Ratio (AR) }\end{array}$ \\
\hline Keywords: & $\begin{array}{l}\text { represent the ratio of energy in DCT coefficients is utilized to identify } \\
\text { the presence of the Primary User (PU) signal. The simulation results show }\end{array}$ \\
\hline $\begin{array}{l}\text { Cognitive radio } \\
\text { DCT }\end{array}$ & $\begin{array}{l}\text { that the proposed method improves PU detection especially at low SNR } \\
\text { values. }\end{array}$ \\
\hline
\end{tabular}

Hybrid sensing

Spectrum sensing

Copyright $\odot 2020$ Institute of Advanced Engineering and Science. All rights reserved.

\section{Corresponding Author:}

Muntasser S. Falih,

Department of Information and Communication Engineering,

Al-Nahrain University,

Baghdad/Jadriyah, Iraq.

Email: mntaser.faleh.1990@ieee.org

\section{INTRODUCTION}

The modern requirements on wireless devices services such as smarts phones, Tablets, and new applications that allow multimedia exchanging becomes massive and bandwidth consumer services. This, in turn, leads to scarcity in spectrum availability. Cognitive Radio (CR) is an emerging technology demanding to achieve Dynamic Spectrum Allocation (DSA) that aims to compensate the spectrum stinginess. According to the Federal Communication Commission (FCC) survey revealed that the daily use of licensed spectrum by the Primary User (PU) is lower than 30\% in some geographic area [1-4]. By using CR, these opportunities can be utilized in spectrum such as in TV band and $4 \mathrm{G}$ cellular networks to overcome the spectrum problem and optimize resources usage. CR as a system consists of the life cycle the basic and more sensitive step is spectrum sensing cycle. Spectrum sensing is the process that achieved by Secondary User (SU) side to know the PU status which either idle or busy with a purpose to detect the spectrum holes [5-9]. There are many narraw-band spectrum sensing methods such as Matched Filter [10], Cyclostationary [11], Energy Detector [12], features based [13] and eigen value based [14] . Onother hand, there aremany spectrum sensing methods specialized for wide-band channles such as compressive sensing $[15,16]$ and edge based detectiom methods [17]. The main challenge of spectrum sensing is achieve a spectrum sensing method that mixes the sufficient detection accuracy at low SNR values with acceptable processing complexity. Solving this challenge will act to enhance the overall spectrum utilization and increasing the total network throughput. In this paper, a hybrid energy detection method mixes the Conventional Energy Detector (CED) with an assisting sensing module based on the Discrete Cosine Transform (DCT) is proposed. 


\section{RELATED WORKS}

Many efforts are proposed in the literature to improve the detection performance of energy detection based spectrum sensing using a statistical measure of PU and noise signals. For example, in [18] the authors introduced a sensing method use a statistical parameter which represents the ratio between variance and mean values of energy as an indicator whether the received signal is a PU or noise alone. In [19], the authors proposed a spectrum sensing method based on using noise uncertainty factor to update the threshold value of the energy detector. In [20], the authors proposed an adaptive spectrum sensing method based on higher order moment and cumulate with a multilevel threshold for decision stage. There are another efforts to developing CED by utilizing another transformation approaches for example In [21] the authors designed a new energy based spectrum sensing using DCT instead of Discrete Fourier Transform (DFT), this was a good method but not take into account the noise signal recognition from PU signal from DCT coefficient's relationship.

According to the related works above, it can be seen that most of these efforts focused on utilizing complex approaches to achieve high detection accuracy and did not take into account the recognition performance of PU and noisy signals based on variation resulting from transformation of these signals. Another most important note can be seen, is that the all above works did not utilize the traditional energy detection method as assisting module to simplify the detection complexity when the received signal falls in medium SNR range, which in turn can provide acceptable sensing accuracy with low overhead that gives short detection time and increased network throughput. In this paper, a new approach to distinguish between PU and noise only signals by utilizing DCT transform features is proposed. The distribution of energy in DCT sub-bands, fortunately, show a wide variance between PU and noise alone signal cases especially at lower sub-bands. This measure is used to support CED detector when it fails to produce the right decisions at low SNR values

\section{CONVENTIONAL ENERGY DETECTOR (CED)}

Conventional Energy Detector (CED) is the simple context of ED method in which the Secondary User (SU) accumulates the received energy with respect to a certain number of samples (Ns). The binary hypothesis used in the detection criteria is as follows [22]:

$$
y(n)= \begin{cases}w(n) & ; H_{0} \\ s(n)+w(n) & ; H_{1}\end{cases}
$$

Where $\mathrm{y}(\mathrm{n})$ is the received sample, $\mathrm{w}(\mathrm{n})$ is the Additive White Gaussian Noise AWGN sample collected from the transmission channel, $\mathrm{s}(\mathrm{n})$ is the PU signal sample, H0 and $\mathrm{H} 1$ are null and power hypothesis respectively. The test statistic of the received sample is defined as follows:

$$
T=\frac{1}{N s} \sum_{n=1}^{N s}|y(n)|^{2}
$$

Where Ns is the total number of received samples. The distribution of $\mathrm{T}$ is chi-squared with $2 \mathrm{Ns}$ degrees of freedom [23]. The received samples are compared with predefined threshold computed based on Constant False Alarm probability (CPFA) [24, 25]. The performance of the detection in energy detector schemes is evaluated based on Receiver Operation Characteristics (ROC) that showing detection probability (Pd), False Alarm Probability (PFA), Signal to Noise Ratio (SNR), and threshold $(\lambda)$. ROC parameters are computed in AWGN as follows [26].

$$
\begin{aligned}
& \left.\mathrm{P}_{\mathrm{D}=\mathrm{P}} \mathrm{T}>\left.\lambda\right|_{\mathrm{H}_{1}}\right] \mathrm{Q}\left(\frac{\lambda-\mathrm{Ns}(1+\mathrm{SNR})}{\sqrt{2 \mathrm{Ns}(1+\mathrm{SNR})}}\right) \\
& \mathrm{P}_{\mathrm{FA}}=\mathrm{P}\left[\mathrm{T}>\left.\lambda\right|_{\mathrm{H}_{0}}\right] \mathrm{Q}\left(\frac{\lambda-\mathrm{Ns}}{\sqrt{2 \mathrm{Ns}}}\right)
\end{aligned}
$$

Where here Q is complementary Q-function (Marcum), Pd represents the correct detection when PU is present, PFA represents false detection alarm that indicates the presence of PU but, actually it is not there. PD and PFA in (3) and (4) are calculated in case of unity noise variance. From (4) $\lambda$ is calculated as follows:

$$
\lambda=\sqrt{2 \mathrm{Ns}} \mathrm{Q}^{-1}\left(\mathrm{P}_{\mathrm{FA}}\right)+\mathrm{N}_{\mathrm{s}}
$$

where $\mathrm{Q}^{-1}$ is inverse Q-function. The system model of CED method is shown in Figure 1 [7]. 


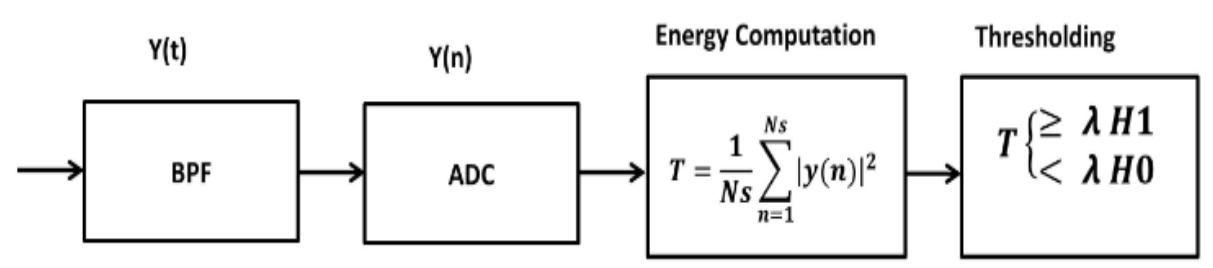

Figure 1. CED block diagram

\section{THE PROPOSED METHOD}

The method mixes the CED with an enhancement sensing module based on DCT statistics as shown in Figure 2. This method has two operation modes. The first mode is performing spectrum sensing using CED method when the received energy is greater or equal to the predefined threshold. When the received energy is less than the predefined threshold, the second mode is initiated where enhancing module based on DCT statistics is activated. The enhancement module will act to make further verification about the hypothesis decision produced by CED energy detector. The verification mechanism can be explained as follows: first DCT transform is computed to received samples using (6) and (7) [27]:

$$
\begin{aligned}
& \mathrm{A}[0]=\frac{1}{\sqrt{\mathrm{N}}} \sum_{\mathrm{n}=0}^{\mathrm{N}-1} \mathrm{a}[\mathrm{n}], \mathrm{M}=0 \\
& \mathrm{~A}[\mathrm{M}]=\frac{2}{\mathrm{~N}} \sum_{\mathrm{n}=0}^{\mathrm{N}-1} \mathrm{a}[\mathrm{n}] \cos \left(\frac{\pi \mathrm{K}(2 \mathrm{n}+1)}{2 \mathrm{~N}}\right), 1 \leq \mathrm{M} \leq \mathrm{N}-1
\end{aligned}
$$

Where $a[n]$ and $A[M]$ are the original and DCT N-point signals. After that, the whole DCT spectrum band (range) of length $\mathrm{N}$ is divided the into $\mathrm{K}$ non-overlapped sub-bands of length $\mathrm{N} / \mathrm{K}$ as shown in Figure 3 such that the ith sub-band has local energy Ei $(\mathrm{i}=1,2, \ldots \mathrm{K})$. The energy of first and last sub- bands (E1, EK) are calculated using (8) and (9) then Average Ratio (AR) between E1 and EK is calculated using (10).

$$
\begin{aligned}
& \mathrm{E}_{1}=\frac{\mathrm{K}}{\mathrm{N}} \sum_{\mathrm{i}=1}^{\mathrm{N} / \mathrm{K}}|\mathrm{y}(\mathrm{i})|^{2} \\
& \mathrm{E}_{\mathrm{K}}=\frac{\mathrm{K}}{\mathrm{N}} \sum_{\mathrm{i}=\mathrm{N}-\frac{\mathrm{N}}{\mathrm{K}}}^{\mathrm{N}}|\mathrm{y}(\mathrm{i})|^{2} . \\
& \mathrm{AR}=\frac{\mathrm{E} 1}{\mathrm{Ek}}
\end{aligned}
$$

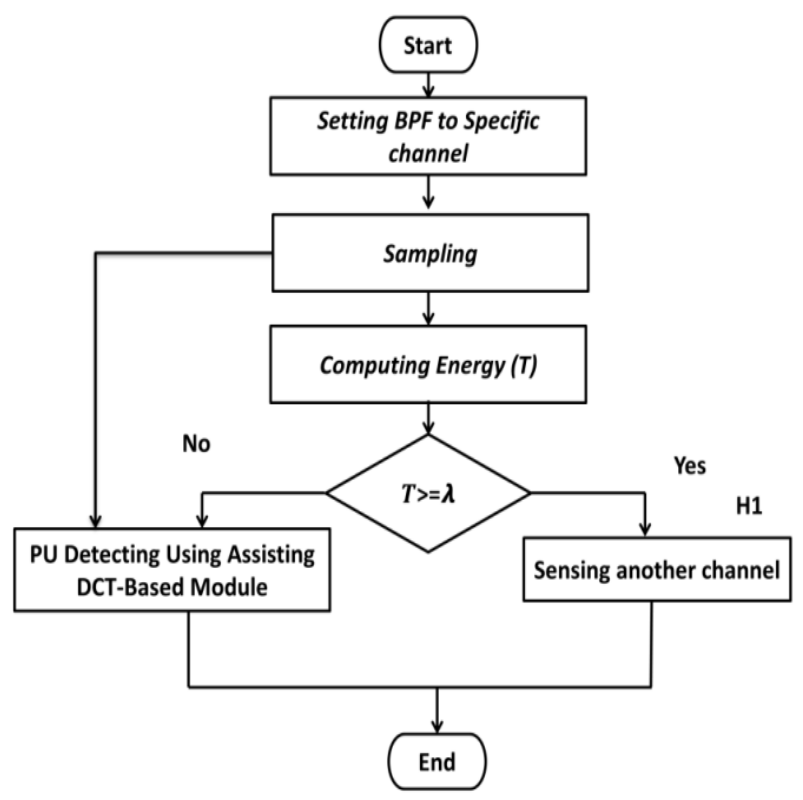

Figure 2. The proposed algorithm flowchart 


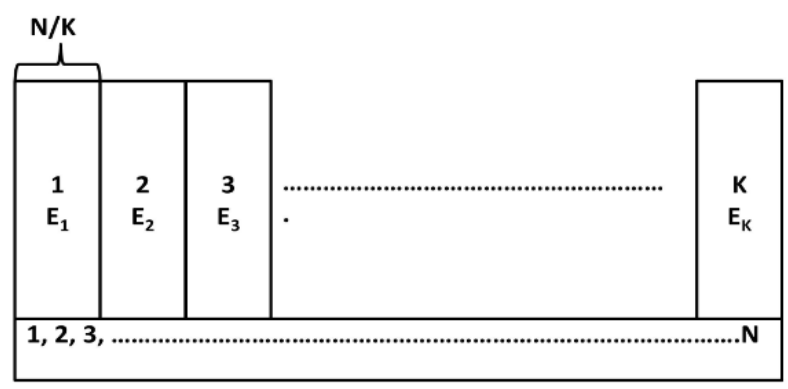

Figure 3. DCT's Sub-bands division

Based on the value of AR, the signal type can be identified which either PU (PU+Noise) or noise only signal. In the case of PU presence, the AR value will be greater than one depending on the SNR value of the transmitted signal. This is related to DCT feature that the lower bands contain the most of signal energy (information), in opposition to the higher bands that contain less energy. In the case of noise-only signal the AR will be approximately unity because there is no source of information except the noise and each sub-band approximately collects the same amount of energy. Figure 4 and Figure 5 show the testing of AR factor in two scenarios, the first scenario assumes PU is present and the second assumes PU is absent with SNR as a parameter respectively.

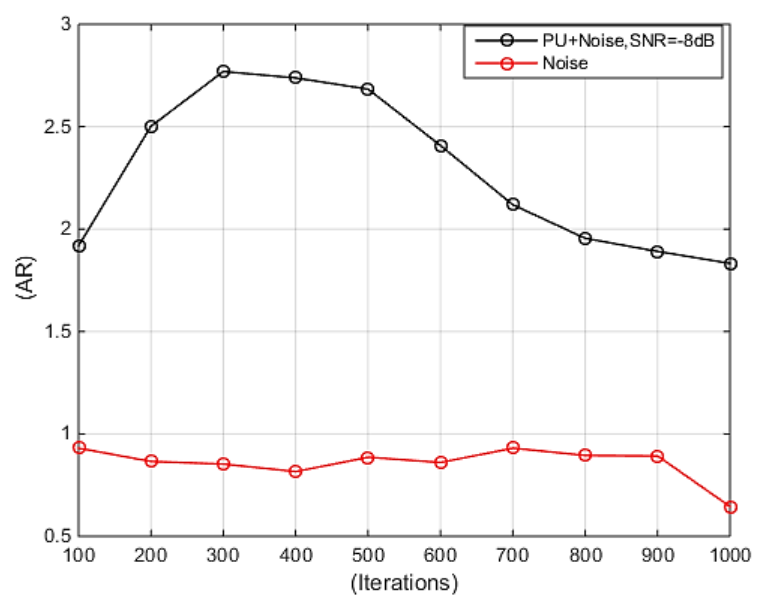

Figure 4. AR factor testing for PU and noise signals at $\mathrm{SNR}=-8 \mathrm{~dB}$

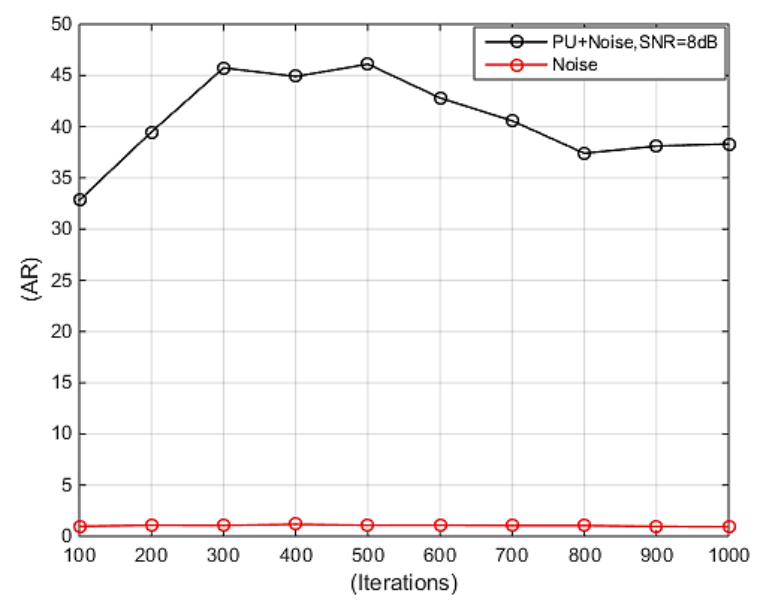

Figure 5. AR factor testing for PU and noise signals at $\mathrm{SNR}=8 \mathrm{~dB}$

From Figure 4 and Figure 5 it can be seen that the value of AR provides an excellent measure to the presence or absence of the PU signal. The rounding of AR will be to unity in case of noise only signal and greater than one in case of PU presence; meanwhile, it can be used as a new threshold for the use at the detection in CED assisting module. The detection mechanism is achieved by comparing the value AR with value of " 1 ", if the value of AR less or equal to 1 the hypothesis is H0; otherwise it is H1. The flowchart of the CED assisting sensing module is shown in Figure 6. The use of this two- mode sensing scheme will provide a good compromise between low complexity provided by CED at high SNR values and accuracy provided by DCT at low SNR values.

The detection probability of the proposed method (PDPRO) is a composite detection probability includes detection probability of CED and the DCT based assisting module as in (11).

$$
\mathrm{PD}_{\mathrm{PRO}}=\mathrm{P}_{\mathrm{INCED}} * \mathrm{PD}_{\mathrm{CED}}+\left(1-\mathrm{P}_{\mathrm{INCED}}\right) * \mathrm{PD}_{\mathrm{DCT}}
$$

where $P_{I N C E D}$ is the probability of falling in CED sensing event, $P D_{C E D}$ is the detection probability of the CED method, and $P D_{D C T}$ is the detection probability of DCT based assisting module. 


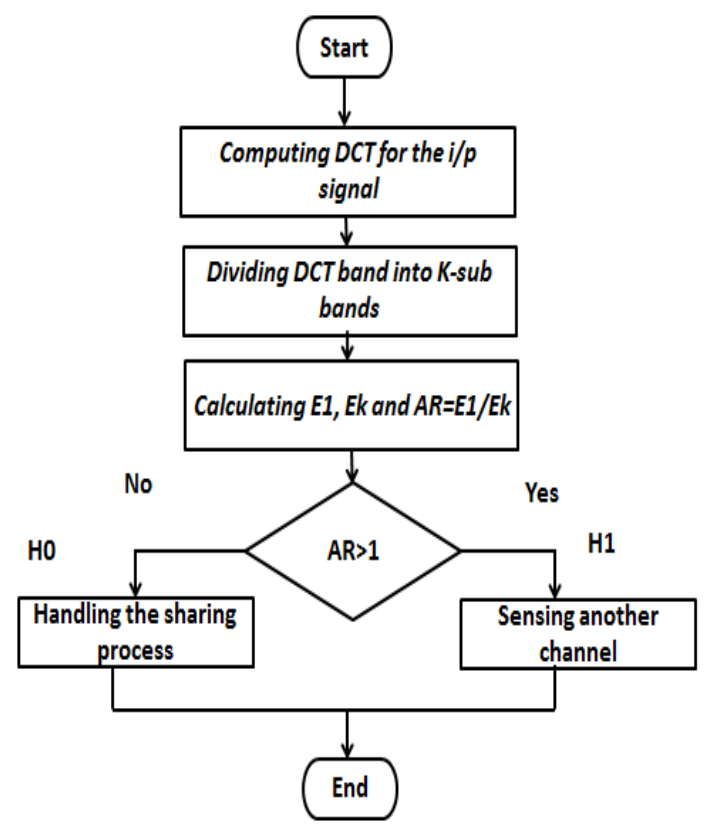

Figure 6. Flowchart of CED assisting sensing module based on DCT

\section{RESULTS}

The proposed method is simulated using MATLAB. The evaluation has been tested for Local Sensing (LS) non- cooperative scenario showing the ROC with different values of $\mathrm{N}_{\mathrm{S}}, \mathrm{P}_{\mathrm{FA}}$ and channels types. The simulation parameters used are given in Table 1. Figure 7 and Figure 8 show the performance of the proposed method versus CED in AWGN channel at $\mathrm{N}_{\mathrm{S}}=1000, \mathrm{P}_{\mathrm{FA}}=0.001$ and $\mathrm{P}_{\mathrm{FA}}=0.01$ respectively. It can be seen from these figures that the proposed method significantly improve the detection probability compared to CED method and this improvement increases as $\mathrm{P}_{\mathrm{FA}}$ decreases. For instance, at $\mathrm{SNR}=-9 \mathrm{~dB}$, the detection probability is improved by $95 \%$ and $90 \%$ using the proposed method when $\mathrm{P}_{\mathrm{FA}}$ is 0.001 and 0.001 respectively. Also, we notice from the performance curves that the detection probability of the proposed method reaches its optimum value of one in about $4 \mathrm{~dB}$ SNR earlier than that of CED method.

Figure 9 shows the performance of proposed and CED methods in Rayleigh fading channel at $\mathrm{NS}=1000$ samples and $\mathrm{PFA}=0.001$. Figure 10 shows the performance of the proposed method at a different number of received samples. From Figure 9 it can be seen the proposed method achieves gain of $20 \%$ improvement in detection energy at $\mathrm{SNR}=-11 \mathrm{~dB}$, while in Figure 10 shows the flexibility of the proposed method to operate in different number of received sample with almost similar performance especially as $\mathrm{Ns}=500$ and $\mathrm{Ns}=250$ sample.

Figure 11 shows the performance of the proposed method compared with the method in [4]. From this figure, it can be seen that our proposed method outperform the method of [4] in detection probabilty. For instance, at $\mathrm{SNR}=-10 \mathrm{~dB}, \mathrm{Pd}$ is incresed from 0.5 to 0.8 by improvement factor of $60 \%$. Also, we notice that the detection probability of the proposed method reaches its optimum value of one in about 3.5 dB SNR earlier than that of the method in [4]. Finally, the complexity of the proposed method evaluated using sensing time as depicated in Figure 12. This figure shows the Simulation time comparison between proposed method and CED. From this figure it can be seen that proposed method time consumer than CED at low SNR values when it operate DCT based sensing module, then it return to normal state when CED is operating at high SNR values.

Table 1. Simulation Parameters

\begin{tabular}{ll}
\hline Parameter & Value \\
\hline PU signal Type & QPSK \\
Channel Type & AWGN and Rayleigh fading \\
$\mathrm{P}_{\mathrm{FA}}$ & $10^{-2}$ and $10^{-3}$ \\
Number of Samples $\mathrm{N}_{\mathrm{s}}$ & 1000,500 and 250 \\
SNR Range & -15 to $0 \mathrm{~dB}$ \\
\hline
\end{tabular}




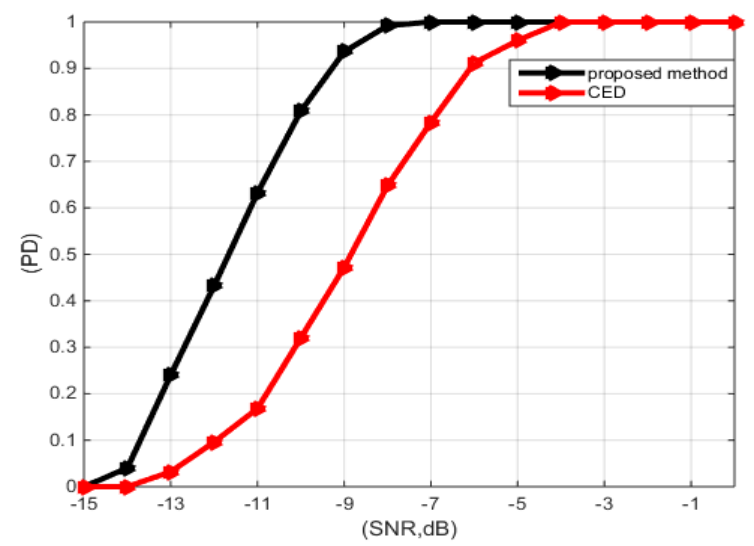

Figure 7. Performance of the proposed method with $\mathrm{CED}$ at $\mathrm{PFA}=0.001$ and $\mathrm{NS}=1000$

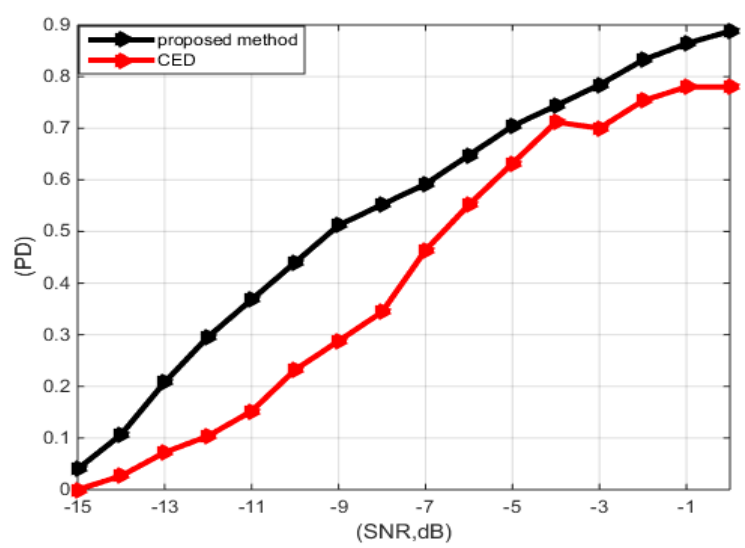

Figure 9. Performance of the proposed method and CED in Rayleigh fading channel at PFA $=0.001$ and $\mathrm{NS}=100$

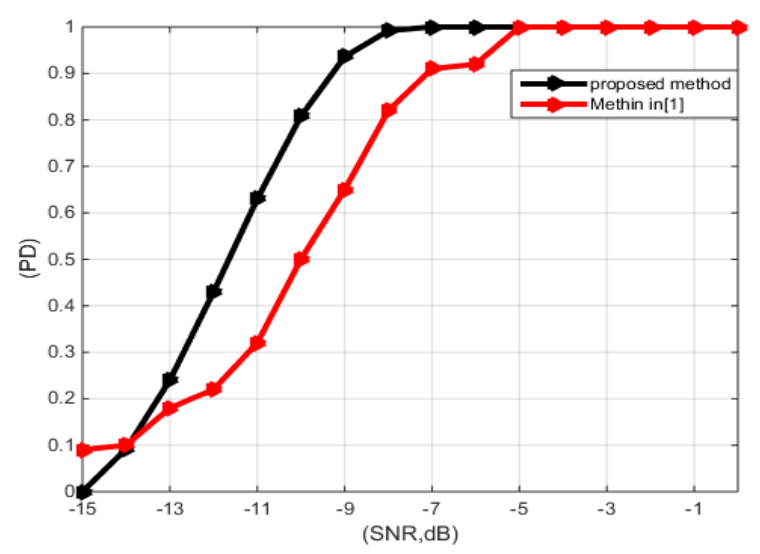

Figure 11. Performance comparison of the proposed method with method in [4]

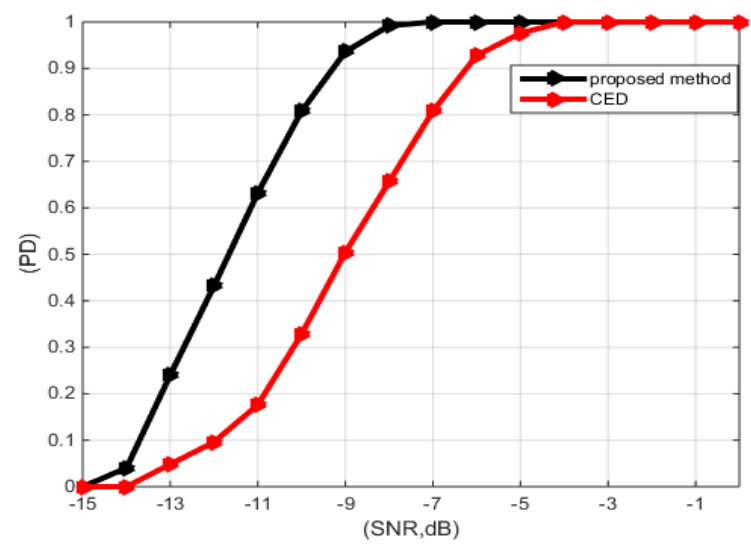

Figure 8. Performance of the proposed method with $\mathrm{CED}$ at $\mathrm{PFA}=0.01$ and $\mathrm{NS}=1000$ Performance of the proposed method with CED at PFA $=0.001$ and $\mathrm{NS}=1000$

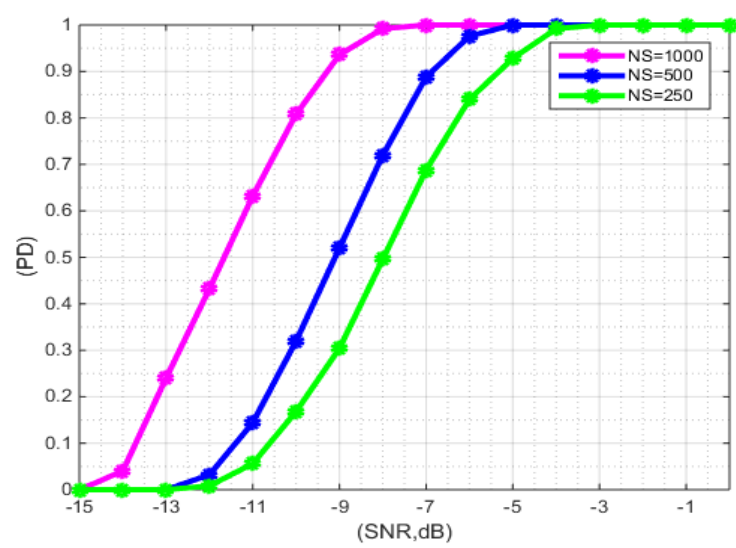

Figure 10. Performance of the proposed method at different NS in AWGN

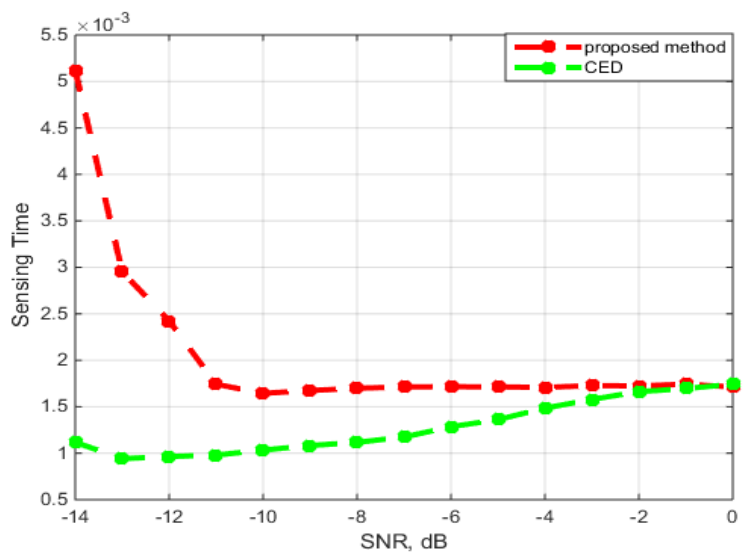

Figure 12. Complexity performance evaluation 


\section{CONCLUSION}

In this paper, a hybrid blind spectrum sensing method has been presented. This method mixes CED with sensing assisting module based on DCT. This method operates in CED mode when received signal energy equal or greater than the threshold value, and operates the assisting sensing module mode when the energy falls below the threshold value. The result showed that the proposed method over perform CED in both types of tested channels, for an instant in AWGN the detection probability enhanced by $95 \%$ at SNR of $-9 \mathrm{~dB}$. As well as in fading channel detection probability has been enhanced by $90 \%$ at SNR of $-9 \mathrm{~dB}$. According to the provided advantages the proposed spectrum sensing method, it represents a suitable method for sensing a low SNR for different signal type without synchronization due to it is blindness nature with energy saving facility that resulted from the switching between CED and the proposed sensing module with respect to the received signal strength.

\section{REFERENCES}

[1] Spectrum Policy Task Force Report, E.D.N. 02-135, Fed. Commun. Commission, Washington, DC, 2002.

[2] J. Mitola, "Cognitive radio: An integrated agent architecture for software defined radio," Dr.Tech. Dissertation, Roy. Inst. Technol., Stockholm,Sweden, 2000.

[3] S. Haykin, "Cognitive radio: Brain-empowered wireless communications," IEEE J. Sel. Areas Commun., vol. 23, no. 2, pp. 201-220,Feb. 2005.

[4] Unlicenced Operation in the TV Broadcast Bands; Additional Spectrum for Unlicensed Devices Below $900 \mathrm{MHz}$ and in the 3 GhzBand, FCC-04-113, Fed. Commun. Commission, Washington, DC, Nov. 2004.

[5] H. Sarvanko, M. Mustonen, A. Hekkala, A. Mammela, M. Matinmikko, and M. Katz, "Cooperative and noncooperative spectrum sensing techniques using Welch's periodogram in cognitive radios," in First International Workshop on Cognitive Radioand Advanced Spectrum Management, 2008. CogART 2008, pp. 1-5, 2008.

[6] L. Khaled and Z. Wei, "Cooperative Communications for Cognitive Radio Networks," Proceedings of the IEEE, vol. 97, pp. 878-893, 2009.

[7] Muntaser S. Falih and Hikmat N. Abdullah, "Evaluation of Different Energy Based Spectrum Sensing Approaches in Cognitive Radio System: Practical Perspective,” IJSR, Volume 6 Issue 12, December 2018.

[8] S. J. Shellhammer, et al. "Spectrum sensing in IEEE 802.22," IAPR Wksp. Cognitive Info. Processing, pp.9-10, 2008.

[9] T. X. Brown, et al, "A survey of TV white space measurements, ” International Conference on Infrastructure and eServices for Developing Countries, Springer International Publishing, p. 164-172, 2014

[10] Cabric D, Tkachenko A, Brodersen RW, "Spectrum sensing measurements of pilot, energy, and collaborative detection," IEEE Mil Commun Conf (MILCOM) 2006:1-7, 2006.

[11] A. Kumar and N Kumar. P "OFDM system with cyclostationary feature detection spectrum sensing”, KICS, 2018.

[12] S. Kumar and J. Mehdi. "Sensing performance of energy detector in cognitive radio networks", International Journal of Information Technology, Volume 11, Issue 4, pp 773-778, December 2019.

[13] J, Gibson and A, Zafar "Cyclostationary spectrum detection in cognitive radios," IET Seminar on Cognitive radio and software defined radios: technologies and techniques, pp 1-5, 2008.

[14] Y. Zeng and Y. Liang, C., "Spectrum-sensing algorithms for cognitive radio based on statistical covariances". IEEE Trans Veh Technol, 58(4):1804-1815, 2009.

[15] D. L. Donoho, "Compressed sensing," IEEE Transactions on Information Theory, vol. 52, pp. 1289-1306, 2006.

[16] F. Salahdine, N. Kaabouch, and H. El Ghazi, "A survey on compressive sensing techniques for cognitive radio networks," Physical Communication, vol. 20, pp. 61-73, 2016.

[17] T. Zhi and G. B. Giannakis, "A Wavelet Approach to Wideband Spectrum Sensing for Cognitive Radios," in 1st International Conference on Cognitive Radio Oriented Wireless Networks and Communications, pp. 1-5, 2006.

[18] Zhang W., Jing X. and Li J., "An Energy Detection Based on Coefficient of Variation for Spectrum Sensing in Cognitive Radio", In: Sun S., Chen N., Tian T. (eds) "Signal and Information Processing, Networking and Computers", ICSINC 2017. Lecture Notes in Electrical Engineering, vol. 473. Springer, Singapore, 2018.

[19] Hossam M. Farag and Ehab Mahmoud Mohamed, "Improved Cognitive Radio Energy Detection Algorithm Based upon Noise Uncertainty Estimation," in Proc. IEEE-National Radio Science Conference (NRSC 2014), Cairo, Egypt, Apr, pp. 107-115, 2014.

[20] Ahmed A. Thabit a, Dr. Hadi T. Ziboon, "A new proposed adaptive cognitive radio detection system design based on statistical feature for different modulation schemes," International Conference on Change, Innovation, Informative and Disruptive Technology ICCIIDT 16, London- U.K, October 11, 12, 2016.

[21] E. H. Salman and et al., "On the Energy Detection Performance Based Welch's DCT Algorithm in Cognitive Radio Systems," 1st International Scientific Conference of Engineering Sciences-3rd Scientific Conference of Engineering Science (ISCES), 2018.

[22] Muntaser S. Falih and Hikmat N. Abdullah, "Double Threshold with Knowledge Based Decision Spectrum Sensing Method", Journal of Advanced Research in Dynamical and Control Systems, Issue 13, pp. 2169-2175, 2018.

[23] HM. Farag, and M. Ehab, "An efficient dynamic thresholds energy detection technique for cognitive radio spectrum sensing," International Conference on Computer Engineering, pp. 139-144, 2014.

[24] S. M. Kay, "Fundamentals of Statistical Signal Processing: Detection Theory", vol. 2. Prentice Hall, 1998.

[25] W. Baldygo, R. Brown, M. Wicks, and P. Antonik, "Artificial intelligence applications to constant false alarm rate (CFAR) processing," Radar Conference, pp. 275-280, 1993. 
[26] J. Song, Z. Feng, P. Zhang, and Z. Liu, "Spectrum sensing in cognitive radios based on enhanced energy detector," IET Communication., vol. 6, no. 8, pp. 805-809, May. 2012.

[27] A. V. Oppenheim, R. W. Schafer, and J. R. Buck, "Discrete-time signal processing," vol. 2: Prentice-hall Englewood Cliffs, NJ,1989.

\section{BIOGRAPHIES OF AUTHORS}

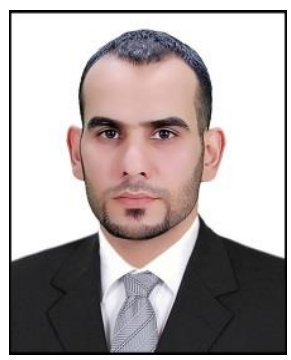

Muntasser S. Falih was born in Al-Imara, Iraq in 1990. He obtained his B.Sc. in Information and Communication Engineering in 2013 at University of Baghdad, Iraq, M.Sc. in Networking Engineering in 2016 at Al-Nahrain University, Iraq and he is now a Ph.D. student in Information and Communication Engineering at Al-Nahrain University, Iraq. He is work on the project of developing the cognitive radio sensing algorithms as Ph.D. research. He interested in subject of wireless communications, security and cognitive radio networks.

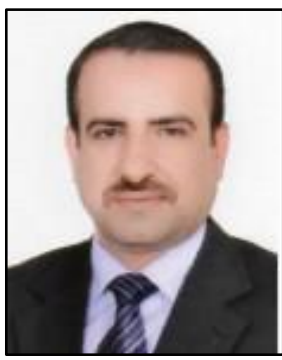

Hikmat. N. Abdullah was born in Baghdad, Iraq in 1974. He obtained his B.Sc. in Electrical Engineering in 1995, M.Sc. in Communication Engineering in 1998 at Al-Mustansiryah University, Iraq and Ph.D. in Communication Engineering in 2004 at University of Technology, Iraq. From 1998 to 2015 he worked as lecturer/associate professor in the Electrical Engineering Department, at Al-Mustansiryah University, Iraq. Since the beginning of 2015 he works as associate professor/ full professor in college of Information Engineering at Al-Nahrain University, Iraq. From 2011-2013 he got a research award from International Institute of Education (IIE/USA) at Bonn-Rhein-Sieg university of applied sciences, Germany. He is asenior member of IEEE association since 2014. He is interested in subject of wireless communications, chaotic communications and cognitive radio networks. 